Research Article

\title{
Stress Measurement of Steel Strands Based on System Identification Method
}

\author{
Ji Qian (D), 1,2 Jianbin Li, ${ }^{3}$ Changchun Li $\mathbb{D}^{3},{ }^{3}$ Jianting Zhou $\mathbb{D}^{1,3}$ and Guowen Yao ${ }^{1,3}$ \\ ${ }^{1}$ State Key Laboratory of Mountain Bridge and Tunnel Engineering, Chongqing Jiaotong University, Chongqing, 400074, China \\ ${ }^{2}$ College of Civil and Environmental Engineering, Champaign, University of Illinois at Urbana-Champaign, IL, 61801, USA \\ ${ }^{3}$ College of Civil Engineering, Chongqing Jiaotong University, Chongqing, 400074, China
}

Correspondence should be addressed to Changchun Li; 892792312@qq.com

Received 19 August 2019; Accepted 6 November 2019; Published 20 December 2019

Academic Editor: F. Viadero

Copyright ( 92019 Ji Qian et al. This is an open access article distributed under the Creative Commons Attribution License, which permits unrestricted use, distribution, and reproduction in any medium, provided the original work is properly cited.

\begin{abstract}
Steel strands are crucial components of a prestressed structure, but their performance degrades inevitably with time. Among the existing nondestructive testing methods for measuring the stress state of steel strands, ultrasonic guided wave methods have received the most research attention and are most likely to be applied to actual engineering. This work views the propagation of ultrasonic guided wave as an individual system, and the variations in the stress state in steel strands can be related to the parameters gained by the system identification model. The finite element simulation and experimental results show the propagation characteristics of the guided wave are influenced distinctly by the stress state. The index constructed by the system parameters exhibits good monotonic linear with stress level variation, and the slope of the fitted line from experimental data is similar to the simulation result. The sensor placement and loading path have a limited effect on the stress state and the proposed index.
\end{abstract}

\section{Introduction}

Prestressed steel strands are used widely in civil engineering buildings and are the most important mechanical components of long-span bridges, acting as the main prestressed tendons of girder bridges, suspenders of arch bridges, and cables of cable-stayed bridges. Being in the high-stress state for a long time, the steel strands are very sensitive to environmental erosion and structural creep and the actual retained working stress always decreases, resulting in structural cracking, deflection, and other failures, which finally reduces the bearing capacity and durability of long-span structures. Steel strands are usually protected with concrete or sheaths of high-density polyethylene, which are used as anticorrosion requirements. However, while the anticorrosion performance is enhanced, inspecting and monitoring the steel strands during periodical inspections can be difficult. The detection and evaluation of the stress of in-service steel strands have long been a technical problem in the field of civil engineering. The relatively mature technology for measuring the stress of steel strands focuses on the detection of stress increment and should adopt embedments in its early stage, making it difficult to be applied to in-service prestressed and cable-supported bridges [1].

The use of ultrasonic guided wave (UGW) methods for monitoring the stress status of steel strands has elicited considerable attention in recent years. The change in guided wave velocity has been applied to monitor stress in plates with biaxial loads [2], bolts (to verify tightening) [3], rails [4-6], steel strands [7-9], grouted tendons [10], and pipes [11]. Kwun et al. [12] performed early experimental studies on the effect of stress on guided waves in a strand. They excited guided waves as a whole throughout the cross section of a strand using magnetostrictive sensors. Chen et al. [13] conducted an early study on the fundamental longitudinal guided model $(0,1)$ excited within the individual wires of a strand.

Most studies on stress estimation in the experimental and theoretical aspects are based on the acoustoelastic effect. Group velocity in low-order modes will decrease with the 
increase in the stress of steel strands [14]. However, conducting acoustoelastic measurements is difficult in this case because the acoustoelastic effect is inherently low. The velocity of the first-order longitudinal wave only exhibits 5\% variation when axial stress reaches its maximum value [15]. The acoustoelastic effect also presents a nonlinear behavior, particularly under the conditions of assembled strands and low stress [16]. Di Scalea et al. [17] proposed a similar description that was formulated under the same test conditions used in Washer [16]. However, a sound explanation for these irregularities has yet to be provided.

Another phenomenon in which a portion of the frequency band will disappear from the guided wave frequency spectrum with increasing tensile stress has been discussed. Kwun et al. [12] and $\mathrm{Wu}$ et al. [18, 19] found from their experiment results that the longitudinal modes disappear in certain bands and the center frequency (notch frequency) of the band is logarithmically linear to tension when a steel strand is loaded with an axial force. This phenomenon was also reported in Laguerre et al. [20] when guided wave propagation was compared between stressed and unstressed seven-wire strands.

A semianalytical finite element (SAFE) method has been used recently to study guided waves propagating as a whole within seven-wire strands. Treyssède and Laguerre [21] presented the first SAFE study applied to seven-wire strands. They explained the notch frequency discovered by Kwun et al. [12]. Nucera and Di Scalea [22] studied the effect of stress on higher harmonics in which the generation of a second harmonic from a primary excitation was correlated with stress. Schaal et al. [23] and Treyssède [24] examined energy leakage between adjacent wires in a stressed strand. SAFE was adopted as an effective approximation method for dealing with a regular waveguide. Accordingly, the use of enormous computing resources in a minuscule meshing size was avoided.

The characteristics of guided waves are affected undoubtedly by the stress status of steel strands. However, convincing explanations for these phenomena remain lacking. In this work, seven-core steel strands commonly used in structures and bridges are taken as subjects. Having considered the propagation of the guided wave in steel strands to be an individual system, the parameters of this system are recognized by the system identification method and a relationship between the proposed index composed by model parameters and stress level is constructed through finite element simulation and experiments. Finally, this work discusses the influence of the placement of sensors and loading paths.

\section{System Identification Model and Stress Index}

The propagation of elastic waves in solids is an elastodynamic problem, and the dispersion curve can be solved by incorporating the geometrical and mechanical boundary conditions into the wave equation. For single high-strength steel wire, the classical theory of the cylindrical waveguide can explain the longitudinal waves, bending waves, torsional waves, and other modal curves. However, establishing the mathematical model of guided wave propagation in strands is difficult because of the contact coupling problem of multiple steel wires and no analytical solution exists at present.

When the guided wave propagating within the steel strand is regarded as an individual system, the change of stress status can lead to the variation of system performance (Figure 1). The stress level can be evaluated by analyzing the parameters of the system model. The measured guided wave is a weakly stationary process, and it can be described by an auto-regressive model in time series.

The auto-regressive model is given by

$$
x_{t}=q_{1} x_{t-1}+q_{2} x_{t-2}+\cdots+q_{p} x_{t-p}+e_{t},
$$

where $x_{t}$ is the sample observation, $e_{t}$ is a random noise with zero mean, and $q_{j}(j=1,2, \ldots, p)$ are regression coefficients.

When a time series $\left\{x_{t}\right\}$ is plugged into equation (1), the results can be expressed as follows:

$$
\begin{aligned}
& x_{n+1}=q_{1} x_{n}+q_{2} x_{n-1}+\cdots+q_{p} x_{1}-e_{n+1}, \\
& x_{n+2}=q_{1} x_{n+1}+q_{2} x_{n}+\cdots+q_{p} x_{2}-e_{n+2}, \\
& \quad \vdots \\
& x_{N}=q_{1} x_{N-1}+q_{2} x_{N-2}+\cdots+q_{p} x_{N-n}-e_{N} .
\end{aligned}
$$

Then, equation (2) can be written into matrix form

$$
Y=X \varphi-\varepsilon
$$

where

$$
\begin{aligned}
\mathbf{Y} & =\left[\begin{array}{llll}
x_{n+1} & x_{n+2} & \cdots & x_{N}
\end{array}\right]^{T}, \\
\boldsymbol{\varphi} & =\left[\begin{array}{llll}
q_{1} & q_{2} & \cdots & q_{p}
\end{array}\right]^{T}, \\
\boldsymbol{\varepsilon} & =\left[\begin{array}{llll}
e_{n+1} & e_{n+2} & \cdots & e_{N}
\end{array}\right]^{T}, \\
\mathbf{X} & =\left[\begin{array}{cccc}
x_{n} & x_{n-1} & \cdots & x_{1} \\
x_{n+1} & x_{n} & \cdots & x_{2} \\
\vdots & \vdots & \vdots & \vdots \\
x_{N-1} & x_{N-2} & \cdots & x_{N-n}
\end{array}\right] .
\end{aligned}
$$

The sum of squares of residuals is taken as the criterion function:

$$
\begin{aligned}
\mathbf{J}(\boldsymbol{\varphi}) & =\sum_{i=1}^{N}|\varepsilon|^{2}=\sum_{i=1}^{N}|\mathbf{Y}-\mathbf{X} \boldsymbol{\varphi}|^{2} \\
& =\mathbf{Y}^{T} \mathbf{Y}+\boldsymbol{\varphi}^{T} \mathbf{X}^{T} \mathbf{X} \boldsymbol{\varphi}-\boldsymbol{\varphi}^{T} \mathbf{X}^{T} \mathbf{Y}-\mathbf{Y}^{T} \mathbf{X} \boldsymbol{\varphi} .
\end{aligned}
$$

The necessary condition for finding the least-squares estimate $\varphi$ is

$$
\frac{\partial \mathbf{J}(\varphi) / \partial(\varphi)}{\varphi=\varphi_{\mathrm{ls}}}=0 .
$$

By substituting equation (5) in (6), the following can be obtained:

$$
\mathbf{X}^{T} \mathbf{X} \boldsymbol{\varphi}_{\mathrm{ls}}=\mathbf{X}^{T} \mathbf{Y}
$$




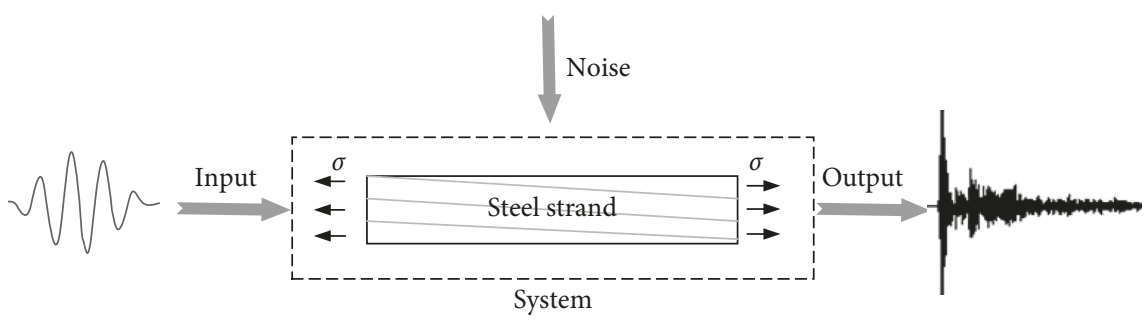

FIGURE 1: System of guided wave propagation.

If $\mathbf{X}^{T} \mathbf{X}$ is full in rank (7), then $\left[\mathbf{X}^{T} \mathbf{X}\right]^{-1}$ exists, and it can be derived as follows:

$$
\boldsymbol{\varphi}_{\mathrm{ls}}=\left(\mathbf{X}^{T} \mathbf{X}\right)^{-1} \mathbf{X}^{T} \mathbf{Y} .
$$

The $\varphi_{\mathrm{ls}}$ is the least-squares estimate of the parameter $q_{j}(j=1,2, \ldots, p)$.

According to the least-squares identification, the most probable value of the unknown model parameter $\varphi$ is obtained when the sum of the cumulative errors between the actual and calculated values reaches the minimum.

The process of measuring the stress status of steel strands based on the auto-regressive model is to extract the autoregressive parameters of the system model as feature vectors and to calculate the distance between different stress levels. While the model in stress level $70 \% f_{\mathrm{pk}}\left(f_{\mathrm{pk}}\right.$ is the ultimate tensile strength) is considered as the reference, the index $I_{\text {stf }}$ is defined as the distance between a certain stress level to reference:

$$
I_{\text {stf }}(i)=\sum_{j=1}^{p}\left|q_{j}^{\text {ref }}-q_{j}^{i}\right|^{2},
$$

where $i$ is a certain stress level, $q_{j}^{\text {ref }}$ is the parameter in the reference model, and $q_{j}^{i}$ is the parameter at a certain stress level.

\section{Finite Element Simulation}

3.1. Finite Element Model. ABAQUS/Explicit is used to simulate the propagation of ultrasonic guided waves in steel strands. The length of the steel strands is $0.52 \mathrm{~m}$. The geometric and material parameters are shown in Table 1.

The finite element model needs eight nodes in a wavelength [25] and a maximum frequency of $500 \mathrm{kHz}$ is considered in this paper to capture accurately the fluctuation effect which indicates $\Delta l \leq \lambda_{\min } /(8-1)=c_{T} /\left(7 \times f_{\max }\right)=$ $3222.6 /(7 \times 500000)=0.92 \mathrm{~mm}$, of which $c_{T}$ is the velocity of transverse waves. The unit size along the axis of the strands is $1 \mathrm{~mm}$ (slightly larger than $0.92 \mathrm{~mm}$ ) and the minimum size of the contact area is $0.1 \mathrm{~mm}$. The model is composed of 1,745,623 8-node hexahedral elements after meshing (Figure 2). Apart from the dimension of grids, time integral step is another important factor in controlling the accuracy of finite element calculation. The response of the structure can be regarded as a combination of modes of each order, and the minimum integral step should be able to solve the highest order modes in the combination of structural response modes. In the process of solving transient dynamics with the finite element method, the time integration step size is generally less than $1 / 20$ of the maximum frequency and should meet the requirements of computing stability at the same time with all free time integral step.

Normal contact between steel wires in strands is simulated with "hard" contact and the tangential contact is simulated with "penalty" friction formula with a friction coefficient of 0.6 [22]. One end of the strand is fixed completely and the other only releases axial displacement, thereby restricting the other direction of freedom.

The entire process of simulation is divided into three stages: axial tension force infliction, guided wave excitation, and guided wave propagation.

Stage 1: tension is imposed at one end of the axial displacement, which is a quasi-static loading process. The amplitude curve of tension should be as smooth as possible and the applied time should be as long as possible to prevent interference signal. In this paper, the smooth amplitude curve is used to load and the loading time is $300 \mu \mathrm{s}$. The loading amplitude curve is shown in Figure 3.

Stage 2: guided wave excitation is carried out at the center of the central steel wire. The excitation is a triangular pulse with a duration of $3 \mu \mathrm{s}$, as shown in Figure 4. The energy of the guided wave generated by the excitation should be much larger than that of the prestressed one to prevent the guided wave signal caused by the excitation load from being submerged by the disturbance signal generated during the prestressed loading process.

Stage 3: after exerting the excitation pulse, the propagation of elastic waves is simulated in the steel strands with $697 \mu$ s.

3.2. Parameters Extraction of Auto-Regression Model. The received waves under different stress level are shown in Figure 5.

The received guided waves are used to establish the autoregression model after the mean and trend terms are removed. The next important step is finding an appropriate order of the model to ensure accuracy. The Akaike information criterion (AIC) assumes that when the density function of a parameter model with $k(k \leq p)$ parameters is denoted as $g\left(y \mid \theta_{k}\right)$ and the maximum likelihood function is denoted $g\left(\hat{\theta}_{k} \mid y\right)$, where $\theta_{k}$ is an unknown parameter and $\hat{\theta}_{k}$ is its maximum likelihood estimation, the AIC is defined as $\mathrm{AIC}=-2 \ln g\left(\widehat{\theta}_{k} \mid y\right)+2 k$. The first term reflects the goodness of model fit, while the second term represents a 
TABLE 1: Geometric and material parameters of steel strands.

\begin{tabular}{lccc}
\hline Geometric parameter & & Material parameter \\
\hline Steel wire diameter, $d_{\mathrm{c}}(\mathrm{mm})$ & 5.08 & Young's modulus, $E(\mathrm{GPa})$ & 196 \\
Strand diameter, $d(\mathrm{~mm})$ & 15.20 & Poisson's ratio, $v$ & 0.29 \\
Peripheral pitch, $h(\mathrm{~mm})$ & 260 & Density, $\rho\left(\mathrm{kg} / \mathrm{m}^{3}\right)$ & \\
Peripheral twist angle, $\beta\left(^{\circ}\right)$ & 7.90 & Ultimate tensile strength, $f_{\mathrm{pk}}(\mathrm{MPa})$ & 7850 \\
\hline
\end{tabular}

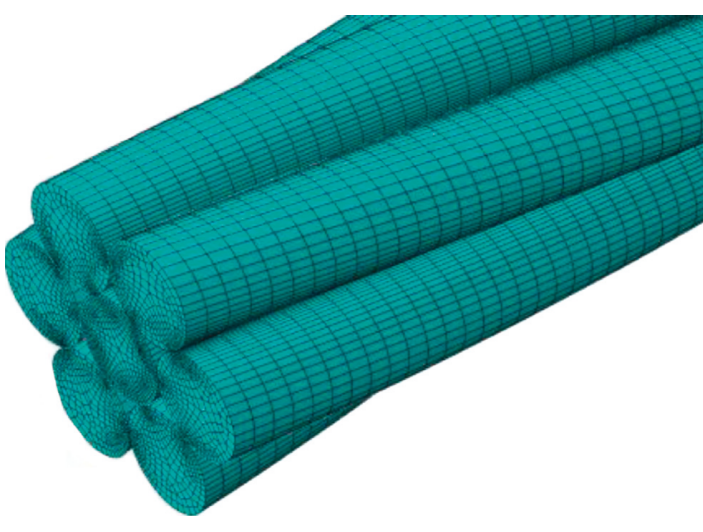

(a)

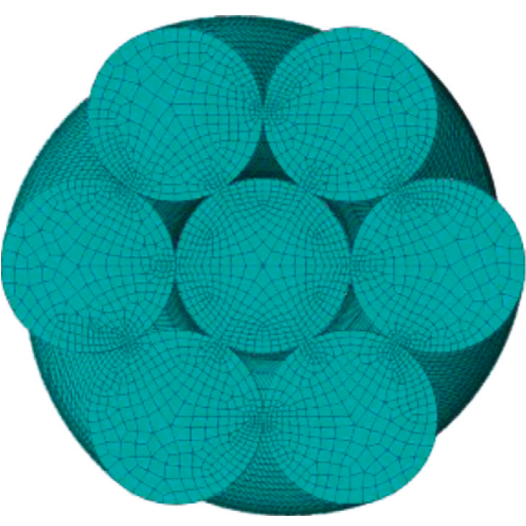

(b)

FIgURE 2: Finite element calculation model of steel strand.

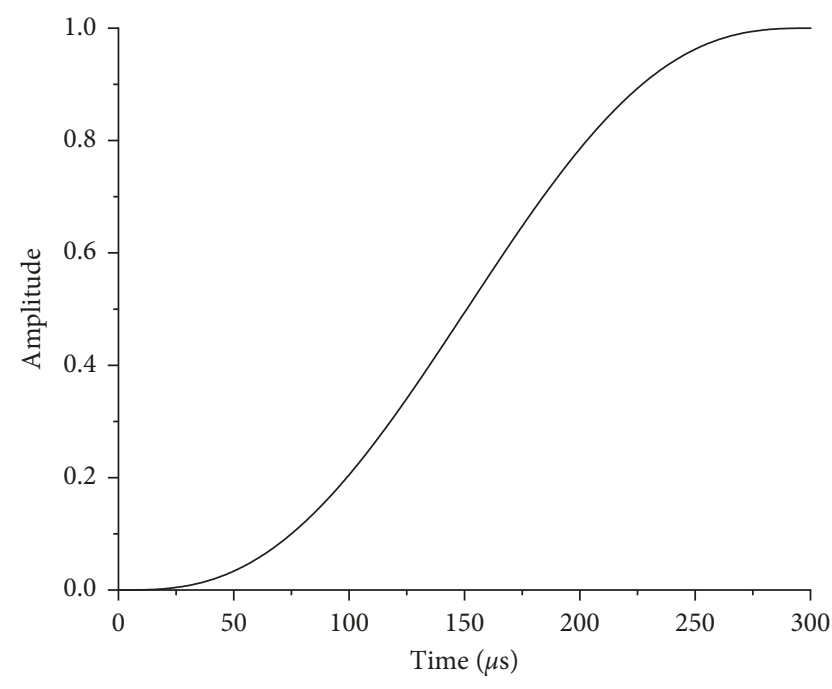

Figure 3: Tension load curve of tension.

"penalty" for the model with more variables. Finally, the final order is the result of weighing the effects of model fitting and the number of variables.

The optimal order of the system is determined as $p=10$ when the AIC is applied to handle the data in this work. Taking the triangular pulse in Figure 4 as the excitation and the received signal under $20 \%-70 \% f_{\mathrm{pk}}$ as the output of the system, the parameters of the auto-regression model are obtained and shown in Table 2.

The increase of tension in steel strands causes the parameters $\left[q_{1} \cdots q_{10}\right]$ of the system model to change significantly and monotonously. In order to verify the accuracy of the identification model of finite element

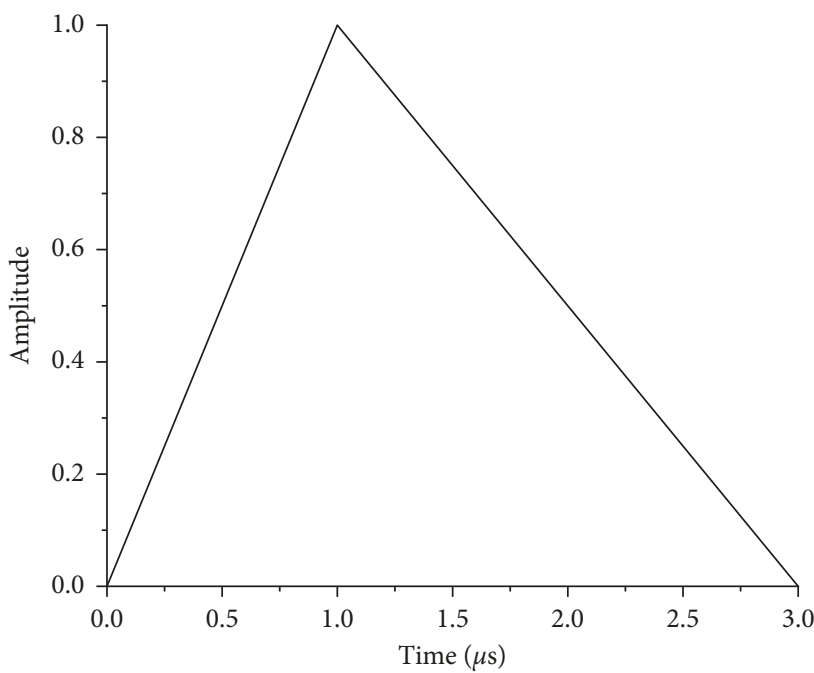

Figure 4: Excitation pulse.

data, the fitting degree is calculated according to te following equation:

$$
\text { fit }=1-\left(\frac{Q}{\sum_{i=1}^{n} y^{2}}\right)^{0.5}
$$

where $Q=\sum_{i=1}^{n}\left(y-y^{*}\right)^{2}$ is the residual sum of squares, in which $y$ is the original data and $y^{*}$ is calculated by the system model.

The waveform shown in Figure 3 is taken as the input of the system, and $\left[q_{1} \cdots q_{10}\right]$ corresponding to $70 \% f_{\mathrm{pk}}$ is taken as the model parameter. The original data and predicted data are shown in Figure 6(a), and the residual error is shown in 

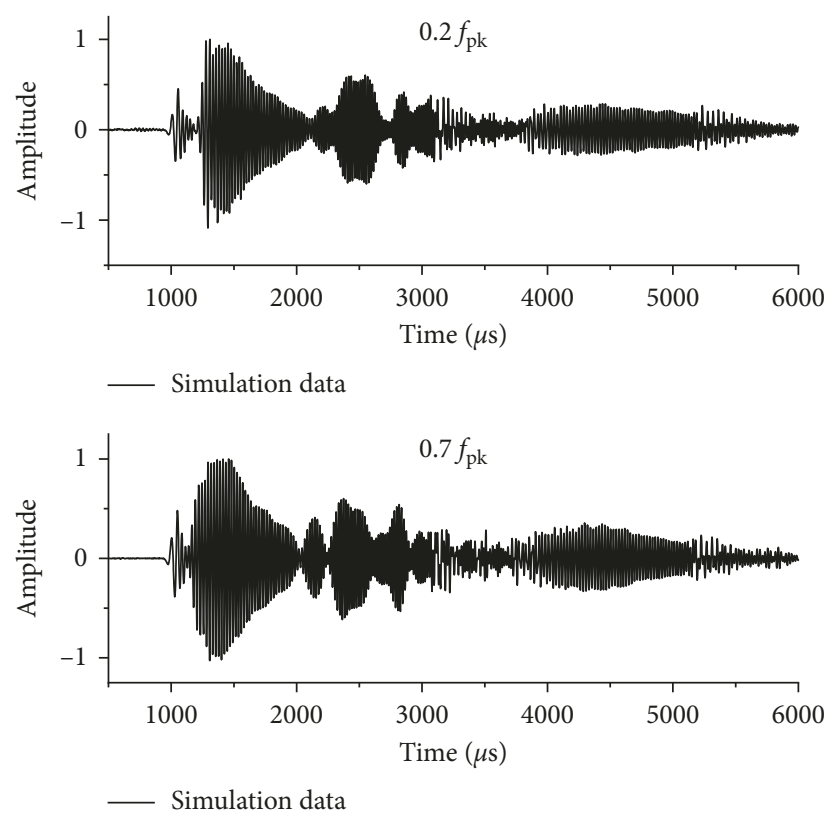

FIGURE 5: Finite element simulation of the guided wave signal.

Figure 6(b). The relative value of residual errors is less than $2 \%$ and the fitting degree reached $98.41 \%$ as calculated by (10), which shows that the auto-regression model can obtain a reasonable order and reliable recognition results.

3.3. Relationship between Stress Level and Index. The parameters of the auto-regression model were calculated by using the optimized order in stepwise loading procedure. The model parameters under the stress level of $70 \% f_{\mathrm{pk}}$ are taken as the reference and the index $I_{\text {stf }}$ is calculated according to (9). The results are shown in Figure 7.

The index of stress evaluation $I_{\text {stf }}$ shows an obvious monotonous variation with the increase in tensile stress. Considering the actual stress state of the structure during the actual operation period, the data do not include those of the stress state under $20 \% f_{\mathrm{pk}}$. The linear fitting of the data is judged by the coefficient $R^{2}=1-\sum_{i=1}^{n}\left(y_{i}-f\left(x_{i}\right)\right)^{2}$ $/ \sum_{i=1}^{n}\left(y_{i}-\bar{y}\right)^{2}$, where $f\left(x_{i}\right)$ is the model predicted stress value, $y_{i}$ is the actual stress value, and the average value is $\bar{y}$. The calculated slope of the fitting line is -5.85 and the definite coefficient is $R^{2}=0.9738$, which presents a clear linear rule.

Taking the recognition index $I_{\text {stf }}$ as an independent variable and the tension force of strands as a dependent variable, the functional relationship between the stress level $\sigma$ and the index $I_{\text {stf }}$ is established as

$$
\frac{\sigma}{f_{\mathrm{pk}}}=-0.171 I_{\mathrm{stf}}+0.662 \text {. }
$$

\section{Experiments}

4.1. Experiments Equipment. The experiment system includes the reaction wall, hydraulic jack, anchor devices, guided wave apparatus, preamplifier, and sensors (Figure 8).
The loading step controlled by a background terminal was set as $10 \%$ of the ultimate tensile strength $\left(f_{\mathrm{pk}}\right)$ and the entire loading process was from $20 \%$ to $70 \% f_{\mathrm{pk}}(52 \mathrm{kN}-182 \mathrm{kN})$. Every step was sustained for $5 \mathrm{~min}$ to excite and collect guided waves. The experiments were performed on eight steel strands.

The material and geometric parameters of steel strands are shown in Table 1. The end faces of the steel strands were polished to ensure good contact between the steel strands and the sensors. The sensors used in this experiment have a wideband frequency response in the range of $100-1000 \mathrm{kHz}$, and the sampling frequency was $2 \mathrm{MHz}$.

The system excitation is a series of single-period sinusoidal pulses with step frequency $\Delta f=50 \mathrm{kHz}$ and is shown in the following equations:

$$
\begin{aligned}
f(t) & =\sum_{i=0}^{\left(f-f_{0}\right) / \Delta f} V_{i}(t) \sin \left(2 \pi\left(f_{0}+i \cdot \Delta f\right)\right), \\
V_{i}(t) & =\left\{\begin{array}{lc}
10, \sum_{j=0}^{i} T_{j} \leq t<\sum_{j=0}^{i} T_{j+1}, \\
0, & \text { else, }
\end{array}\right.
\end{aligned}
$$

where $f_{0}=100 \mathrm{kHz}$ is the origin frequency, $f=1000 \mathrm{kHz}$ is the cut-off frequency, $V_{i}(t)$ is a rectangular window function, $T_{j}$ is the period, and $T_{0}$ is zero.

4.2. Analysis of Experimental Results. The input excitation and measured guide wave under different stress levels are shown in Figures 9 and 10. The excitation waveform remains constant, but the amplitude of the measured waveform decreased obviously with the increase in the stress level. This condition may be attributed to wires having more contact surfaces as stress is enhanced. Accordingly, more guided 
TABLE 2: Identification model parameters in different tension force.

\begin{tabular}{lcccccccccc}
\hline \multirow{2}{*}{ Stress } & \multicolumn{10}{c}{ Parameter } \\
& $q_{1}$ & $q_{2}$ & $q_{3}$ & $q_{4}$ & $q_{5}$ & $q_{6}$ & $q_{7}$ & $q_{8}$ & $q_{9}$ & $q_{10}$ \\
\hline $0.2 f_{\mathrm{pk}}$ & -2.525 & 1.977 & -0.042 & -0.476 & -0.171 & 0.521 & -0.316 & 0.068 & -0.057 \\
$0.3 f_{\mathrm{pk}}$ & -2.491 & 1.955 & -0.158 & -0.364 & -0.075 & 0.348 & -0.205 & 0.030 & -0.083 & 0.060 \\
$0.4 f_{\mathrm{pk}}$ & -2.518 & 2.083 & -0.358 & -0.249 & -0.088 & 0.278 & -0.056 & -0.046 & -0.118 & 0.110 \\
$0.5 f_{\mathrm{pk}}$ & -2.558 & 2.22 & -0.493 & -0.286 & 0.057 & 0.181 & -0.043 & 0.005 & -0.170 & 0.124 \\
$0.6 f_{\mathrm{pk}}$ & -2.653 & 2.546 & -0.852 & -0.226 & 0.241 & -0.123 & 0.346 & -0.332 & 0.016 & 0.069 \\
$0.7 f_{\mathrm{pk}}$ & -2.656 & 2.652 & -1.111 & -0.013 & 0.223 & -0.161 & 0.261 & -0.143 & -0.124 & 0.106 \\
\hline
\end{tabular}

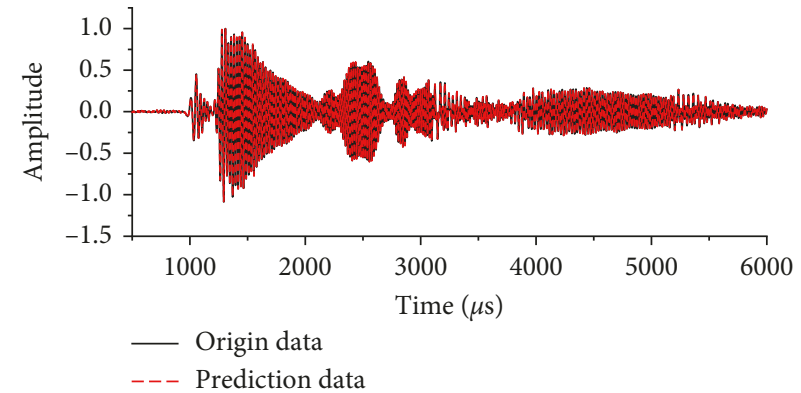

(a)

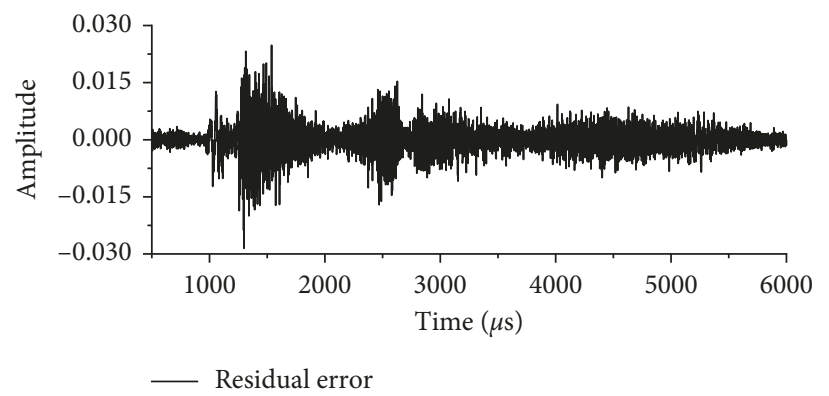

(b)

Figure 6: Fit degree of the recognition model.

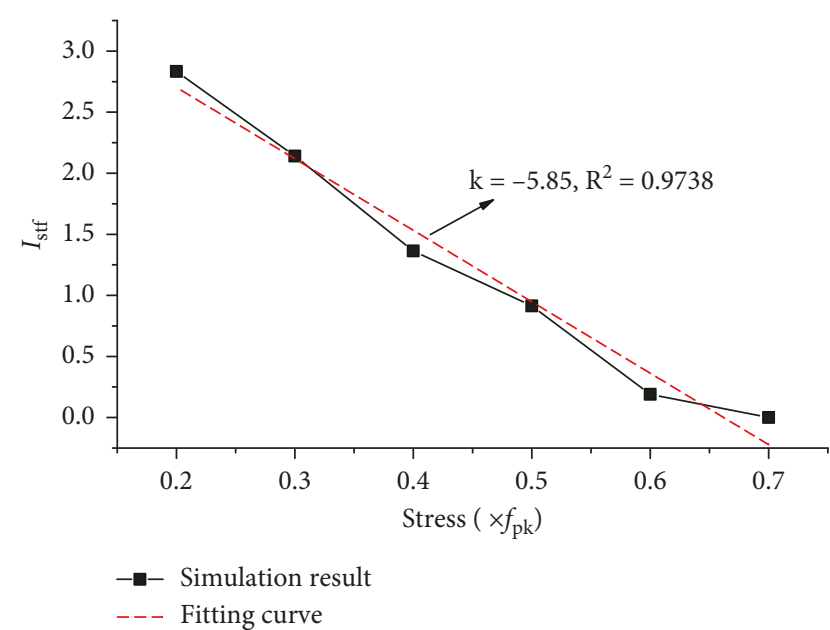

FIgURE 7: Relationship curves between the recognition index and the tensile force.

waves propagate back and forth among wires, causing the energy to be attenuated quickly.

Using the mentioned modeling methods above, the optimal model order of the measured signal is determined to be $p=10$. Eight strands are loaded separately stepwise in experiments, and the same model order is used to calculate the parameters $\left[q_{1} \cdots q_{10}\right]$. The average value $\left[\bar{q}_{1} \cdots \bar{q}_{10}\right]$ of eight strands at $70 \% f_{\mathrm{pk}}$ is taken as the reference value, and the index $I_{\text {stf }}$ is calculated according to equation (9). The results are shown in Figure 11, and the parameters of the fitted line are shown in Table 3.

The index $I_{\text {stf }}$ calculated using the eight independent loading procedures had evident monotonous variation with the increase of the stress level. Using the linear fit, the slope of the fitted line is -5.81 and the determination coefficient is 0.9585 . The experimental results indicate good consistency, reproducibility, and stability.

Taking the index $I_{\text {stf }}$ as an independent variable and the stress level as a dependent variable, the functional relationship between them is established as follows:

$$
\frac{\sigma}{f_{\mathrm{pk}}}=-0.172 I_{\mathrm{stf}}+0.671 \text {. }
$$

Although the slopes of the fitted line have little fluctuation, the line fitted by all experimental data collectively is similar to the finite element result. Thus, the system identification model reveals distinctly the propagation performance of the steel strand and that the parameters of the system can be affected by the corresponding stress status.

\section{Discussion}

5.1. Positions of Sensor Placement. Whether the sensor is arranged at the end section or the side surface, the measured guided wave has different modes, such as longitudinal wave, and bending wave, or the energy proportion among different modes changes. Under the same load condition and excitation input, the index $I_{\text {stf }}$ calculated from the sensors at the end and side positions are shown in Figure 12.

In Figure 12, index $I_{\text {stf }}$ shows the same monotonic variation, regardless of sensors placement. Compared with the sensor arranged on the side surface, the absolute slope of the fitting line at the end section is very close but the determination coefficient is slightly larger. Hence, regardless of whether the sensors are placed at the end or on the side of steel strands, the 


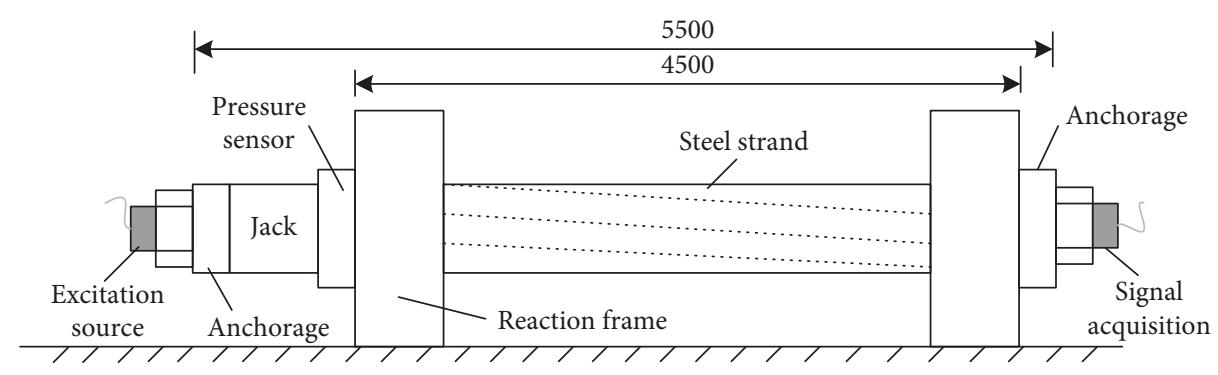

(a)

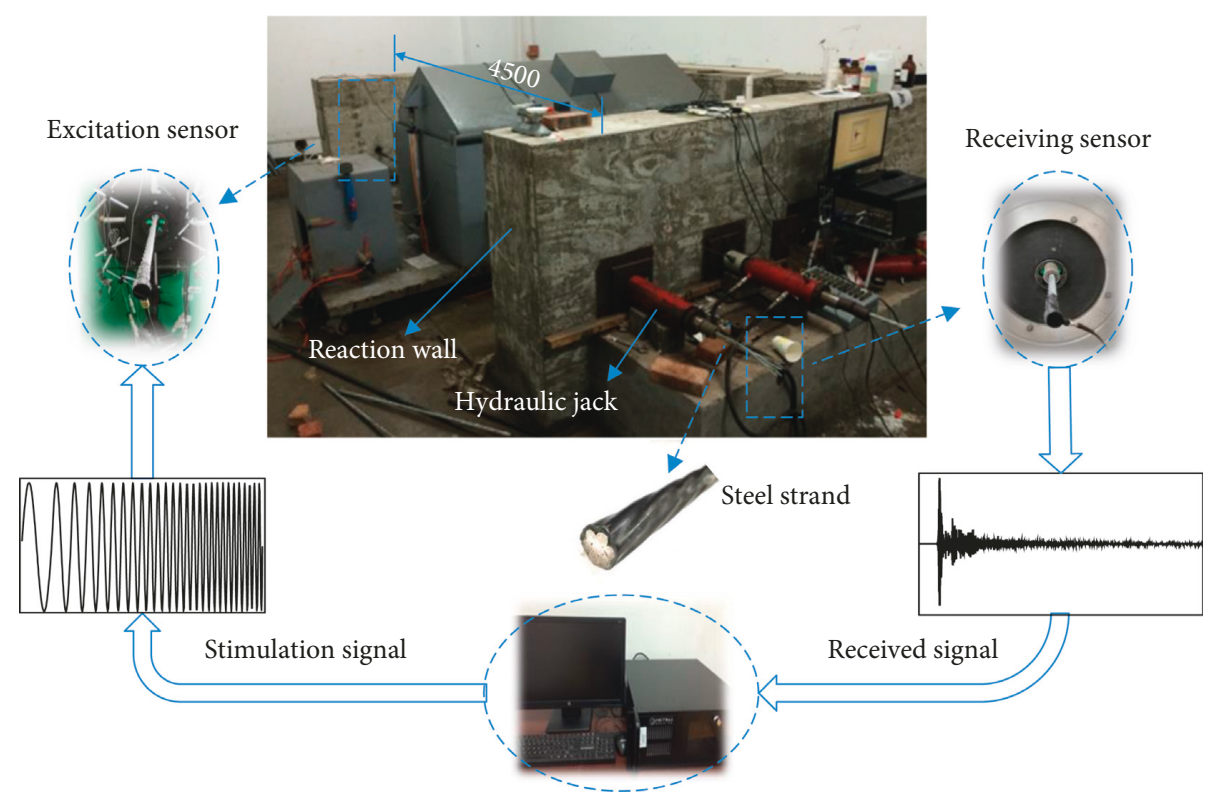

Acoustic emission detector

(b)

FIgURE 8: Design of the experiment system (unit: $\mathrm{mm}$ ). (a) Layout of the experiment system. (b) Equipment of the system.

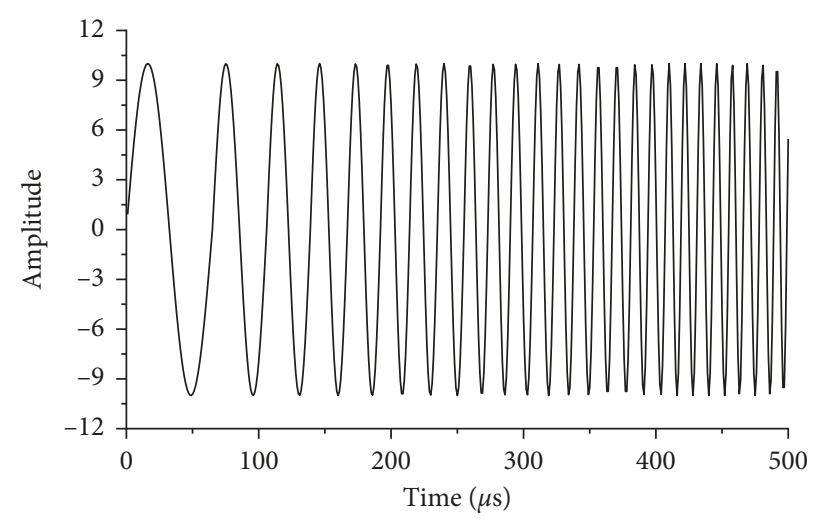

FIGURE 9: Input excitation.

index can reflect the stress state with a good linear law; however, the linear fit has a better effect in the former case.

5.2. Effects of Stress Loading Path. Evaluation of the bearing capacity of the prestressed structure only considers the stress state at some point, which has nothing to do with the loading path. Therefore, the stress index should avoid the effect of stress loading path as far as possible. The index is calculated on the condition of loading and unloading stage, which is shown in Figure 13. The parameters of the fitting line are shown in Table 4.

Figure 13 shows that the index $I_{\text {stf }}$ in the process of loading or unloading is a monotonous linear change. 


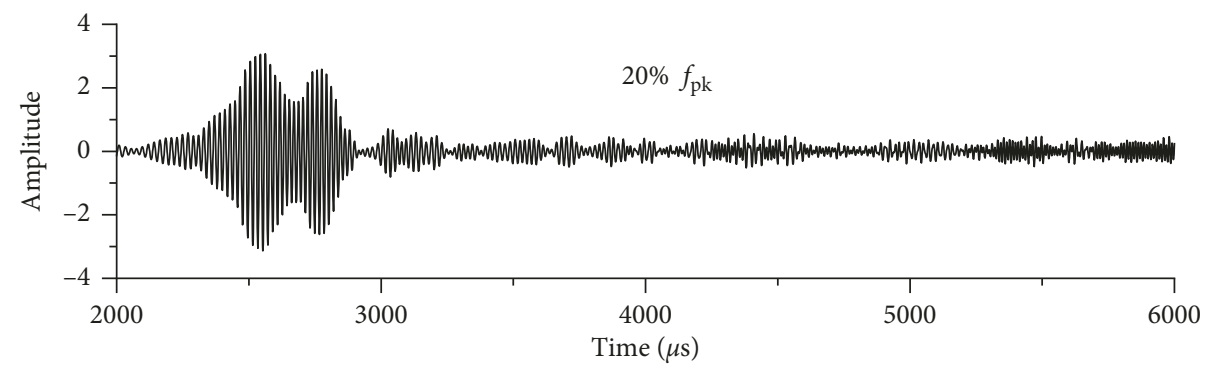

— Experiment data

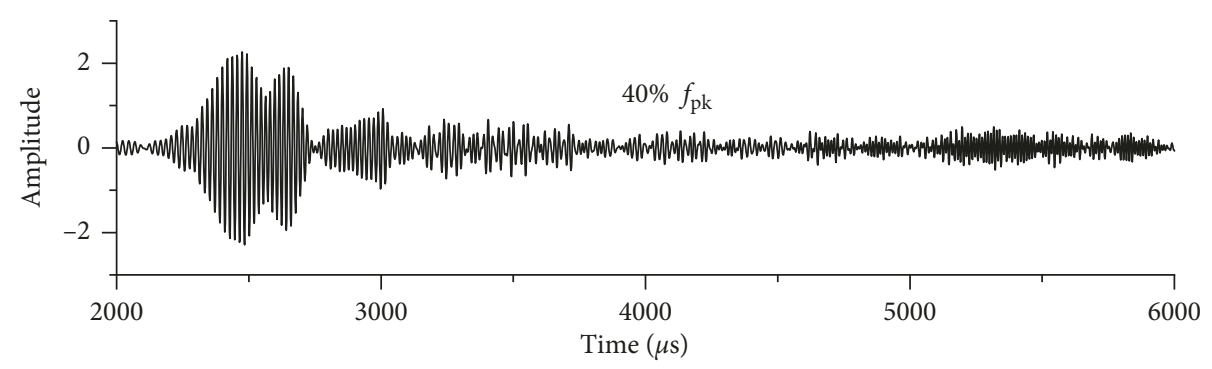

- Experiment data

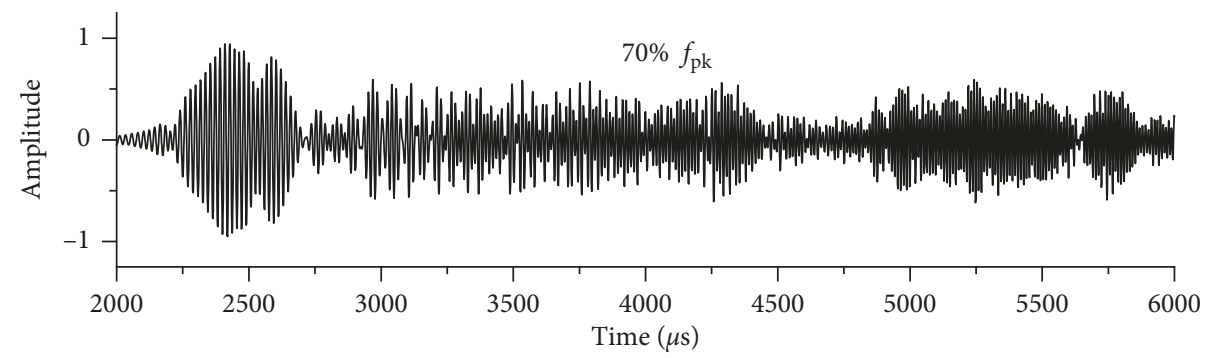

- Experiment data

FiguRe 10: Measured guided waves.

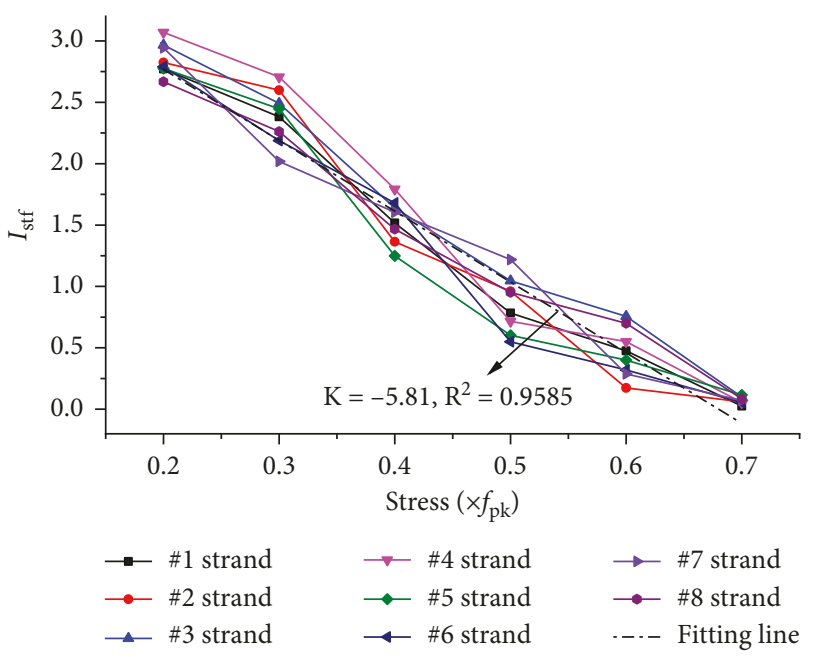

FIgURE 11: Relationship curves between the recognition index and tensile force.

Table 3: The parameters of the fitted line.

\begin{tabular}{|c|c|c|c|c|c|c|c|c|}
\hline Number of strands & 1 & 2 & 3 & 4 & 5 & 6 & 7 & 8 \\
\hline Slope & -5.765 & -6.141 & -5.749 & -6.462 & -5.738 & -5.829 & -5.699 & -5.767 \\
\hline Intercept & 3.920 & 4.093 & 4.087 & 4.389 & 3.846 & 3.886 & 3.921 & 3.920 \\
\hline
\end{tabular}




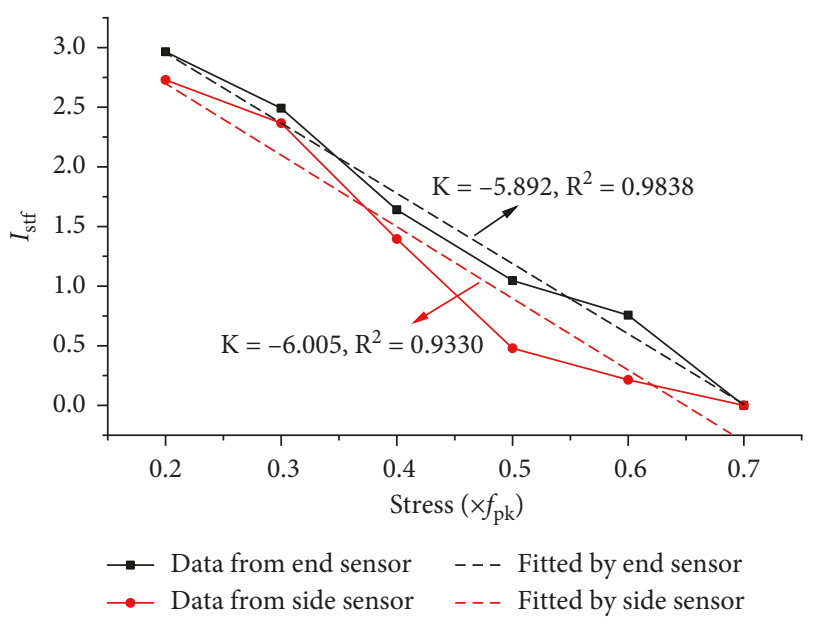

FIGURE 12: Recognition index curve at different sensors position.

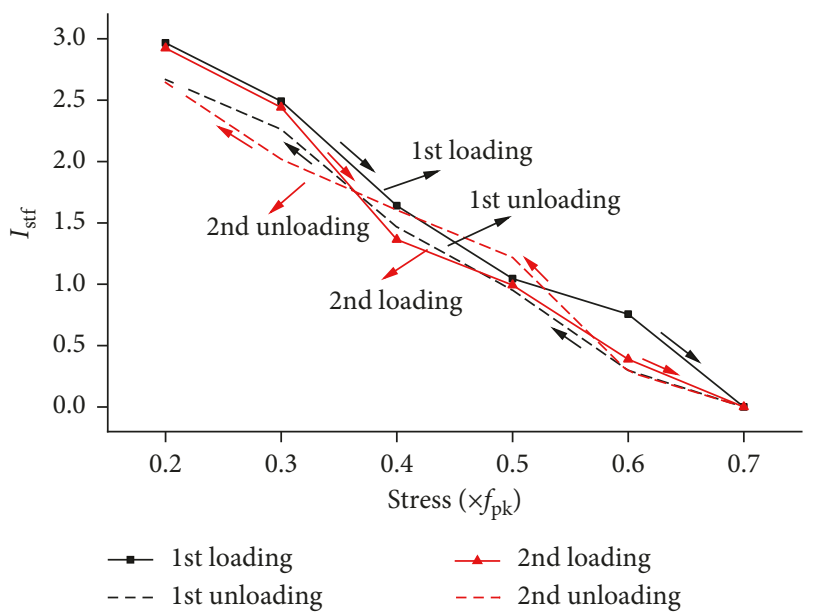

Figure 13: Recognition index curve for loading and unloading process.

TABle 4: Parameters of the fitting line.

\begin{tabular}{lcc}
\hline & $k$ & $R^{2}$ \\
\hline First loading & -5.93 & 0.9842 \\
First unloading & -5.34 & 0.9861 \\
Second loading & -5.85 & 0.9713 \\
Second unloading & -5.29 & 0.9798 \\
\hline
\end{tabular}

Comparing the change of slope in two loading and unloading cycles, the difference between the two loading stages is $1.3 \%$ while that between two unloading stages is $0.9 \%$. Relatively speaking, the slope between the loading and unloading stages change significantly, showing a decrease of $9.9 \%$ and $9.6 \%$, respectively, mainly due to the reading errors caused by the hydraulic lag in load-unload switching.

\section{Conclusions}

Stress measuring of steel strands based on the ultrasonic guided wave is conducted mostly using the theory of cylindrical waveguide, but the difference between those two waveguides is obvious, such as the contact condition among wires and energy leaks at the contact area, which enhances the difficulty in establishing a theoretical resolution in steel strands. In this work, the propagation of the guided wave in steel strands is considered as an individual system and the parameters of this system are extracted using the system identification model. These parameters are used to propose a stress index.

The propagation of the guided wave in steel strands is simulated by the finite element method, and the auto-regressive model in time series is adopted to process the collected signal. A functional relation between the stress state and identification index, which presents a good linear rule, is constructed by optimizing the model order and verifying the accuracy of the system parameters.

The modeling method used in simulation analysis is adopted to process the data from stepwise loading experiments in eight steel strands. Although the slope of the fitted lines displays little fluctuation, the line fitted by all experimental data collectively is close to the simulation result.

The index can reflect the stress state with a good linear law regardless of whether the sensor is placed at the end or on the side of the steel strands; however, the linear fit has a better effect in the former. The slope of the fitted line remains unchanged under the condition of loading and unloading two cycles, which helps in eliminating the effect of loading path.

\section{Data Availability}

The data used to support the findings of this study are available from the corresponding author upon request.

\section{Conflicts of Interest}

The authors declare that they have no conflicts of interest.

\section{Acknowledgments}

This work was supported by the National Natural Science Foundation of China (Grant nos. 51408090 and 51478347); Natural Science Foundation of Chongqing, China (Grant no. cstc2019jcyj-msxmX0624); and Engineering research center of bridge structure and material in mountainous area, Ministry of Education, China (QLGCZX-JJ2017-3).

\section{References}

[1] J. He, Z. Li, J. Teng et al., "Absolute stress field measurement in structural steel members using the Lcr wave method," Measurement, vol. 122, pp. 679-687, 2018.

[2] F. Shi, J. E. Michaels, and S. J. Lee, "In situ estimation of applied biaxial loads with Lamb waves," The Journal of the Acoustical Society of America, vol. 133, no. 2, pp. 677-687, 2013.

[3] S. Chaki, G. Corneloup, I. Lillamand et al., "Combination of longitudinal and transverse ultrasonic waves for in situ control of the tightening of bolts," Journal of Pressure Vessel Technology, vol. 129, no. 3, pp. 383-390, 2007. 
[4] I. Bartoli, R. Phillips, S. Coccia et al., "Stress dependence of ultrasonic guided waves in rails," Transportation Research Record, vol. 2159, no. 1, pp. 91-97, 2010.

[5] F. Chen and P. D. Wilcox, "The effect of load on guided wave propagation," Ultrasonics, vol. 47, no. 1-4, pp. 111-122, 2007.

[6] P. W. Loveday, C. S. Long, and P. D. Wilcox, "Semi-analytical finite element analysis of the influence of axial loads on elastic waveguides," in Finite Element Analysis-From Biomedical Applications to Industrial Developments, D. Moratal, Ed., Intechopen, London, UK, pp. 439-454, 2012.

[7] S. Chaki and G. Bourse, "Guided ultrasonic waves for nondestructive monitoring of the stress levels in prestressed steel strands," Ultrasonics, vol. 49, no. 2, pp. 162-171, 2009.

[8] S. Chaki and G. Bourse, "Stress level measurement in prestressed steel strands using acoustoelastic effect," Experimental Mechanics, vol. 49, no. 5, pp. 673-681, 2009.

[9] J. Qian, X. Chen, L. Sun et al., "Numerical and experimental identification of seven-wire strand tensions using scale energy entropy spectra of ultrasonic guided waves," Shock and Vibration, vol. 2018, Article ID 6905073, 11 pages, 2018.

[10] M. D. Beard, M. J. S. Lowe, and P. Cawley, "Ultrasonic guided waves for inspection of grouted tendons and bolts," Journal of Materials in Civil Engineering, vol. 15, no. 3, pp. 212-218, 2003.

[11] J. Quiroga, R. Villamizar Mejía, L. E. Mujica Delgado et al., "Guided ultrasonic wave for monitoring stress levels in pipelines," in Proceedings of the 7th ECCOMAS Thematic Conference on Smart Structures and Materials (SMART 2015), Ponta Delgada, Azores, Portugal, June 2015.

[12] H. Kwun, K. A. Bartels, and J. J. Hanley, "Effects of tensile loading on the properties of elastic-wave propagation in a strand," The Journal of the Acoustical Society of America, vol. 103, no. 6, pp. 3370-3375, 1998.

[13] H.-L. Chen, Y. I. He, and G. Hota, "Measurement of prestress force in the rods of stressed timber bridges using stress waves," Materials Evaluation, vol. 56, no. 8, pp. 977-981, 1998.

[14] Z. Liu, L. Su, B. Wu et al., "Experimental study on acoustic elastic effect of ultrasonic guided waves in prestressed steel strand," Journal of Mechanical Engineering, vol. 46, no. 2, pp. 22-27, 2010.

[15] J. Qian, Y. A. N. G. Jinchuan, and L. I. Changchun, “Tensile force calculation of steel strands based on guided wave mode bifurcation angles," Journal of Chongqing Jiaotong University (Natural Science), vol. 37, no. 11, pp. 1-7, 2018.

[16] G. A. Washer, R. E. Green, and R. B. Pond Jr, "Velocity constants for ultrasonic stress measurement in prestressing tendons," Journal of Research in Nondestructive Evaluation, vol. 14, no. 2, pp. 81-94, 2002.

[17] F. L. Di Scalea, P. Rizzo, and F. Seible, "Stress measurement and defect detection in steel strands by guided stress waves," Journal of Materials in Civil Engineering, vol. 15, no. 3, pp. 219-227, 2003.

[18] B. Wu, R. Zhang, X. Liu et al., "A new method for tension measurement of steel strand based on notch frequency characteristics of longitudinal mode ultrasonic guided waves," Journal of Mechanical Engineering, vol. 52, no. 12, pp. 9-15, 2016.

[19] X. Liu, B. Wu, F. Qin, C He, and Q Han, "Observation of ultrasonic guided wave propagation behaviours in prestressed multi-wire structures," Ultrasonics, vol. 73, pp. 196205, 2017.

[20] L. Laguerre, J.-C. Aime, and M. Brissaud, "Magnetostrictive pulse-echo device for non-destructive evaluation of cylindrical steel materials using longitudinal guided waves," Ultrasonics, vol. 39, no. 7, pp. 503-514, 2002.

[21] F. Treyssède and L. Laguerre, "Investigation of elastic modes propagating in multi-wire helical waveguides," Journal of Sound and Vibration, vol. 329, no. 10, pp. 1702-1716, 2010.

[22] C. Nucera and F. L. Di Scalea, "Monitoring load levels in multi-wire strands by nonlinear ultrasonic waves," Structural Health Monitoring: An International Journal, vol. 10, no. 6, pp. 617-629, 2011.

[23] C. Schaal, S. Bischoff, and L. Gaul, "Energy-based models for guided ultrasonic wave propagation in multi-wire cables," International Journal of Solids and Structures, vol. 64-65, pp. 22-29, 2015.

[24] F. Treyssède, "Investigation of the interwire energy transfer of elastic guided waves inside prestressed cables," The Journal of the Acoustical Society of America, vol. 140, no. 1, pp. 498-509, 2016.

[25] D. Datta and N. N. Kishore, "Features of ultrasonic wave propagation to identify defects in composite materials modelled by finite element method," NDT \& E International, vol. 29, no. 4, pp. 213-223, 1996. 


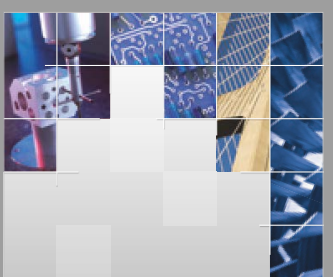

\section{Enfincering}
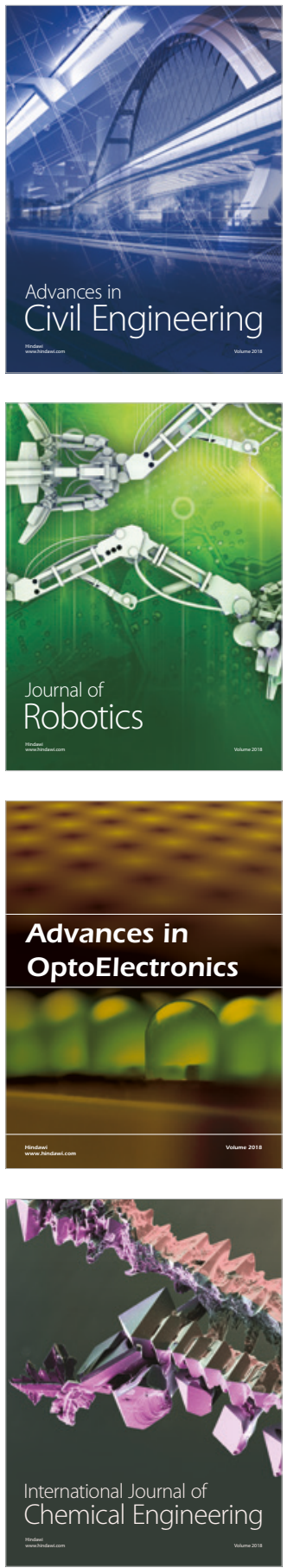

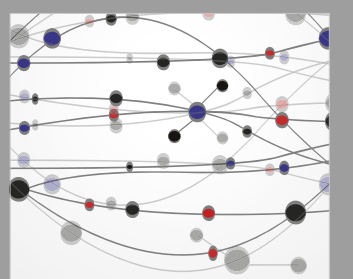

\section{Rotating \\ Machinery}

The Scientific World Journal

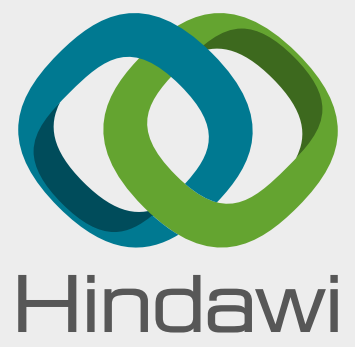

Submit your manuscripts at

www.hindawi.com
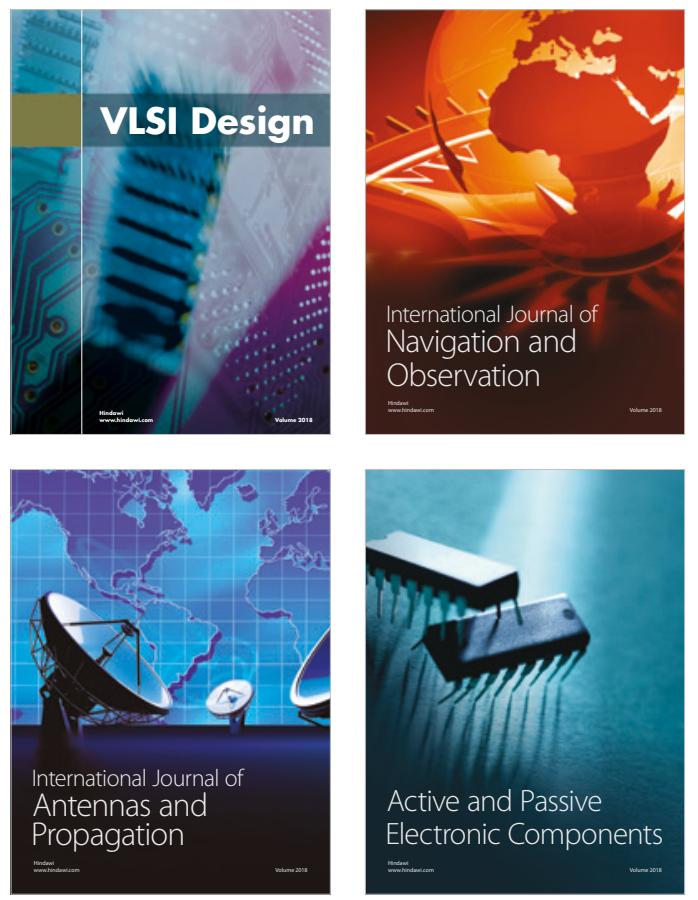
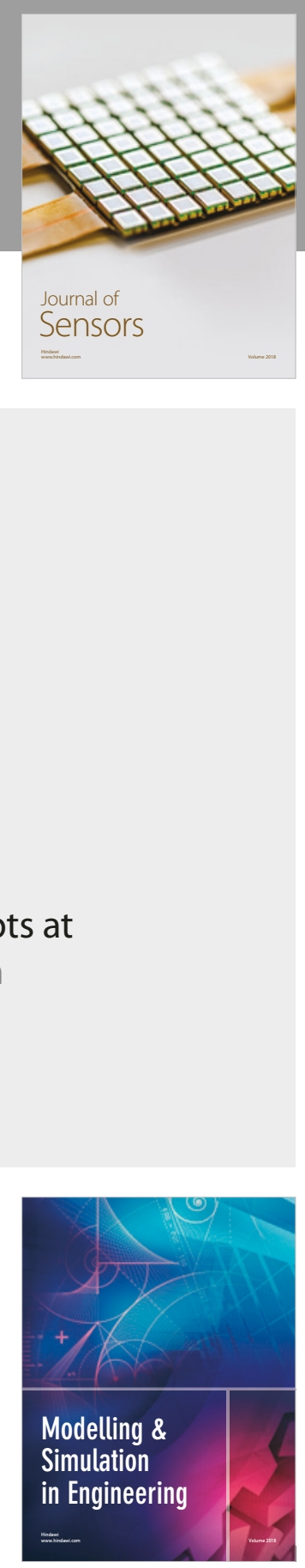

\section{Advances \\ Multimedia}
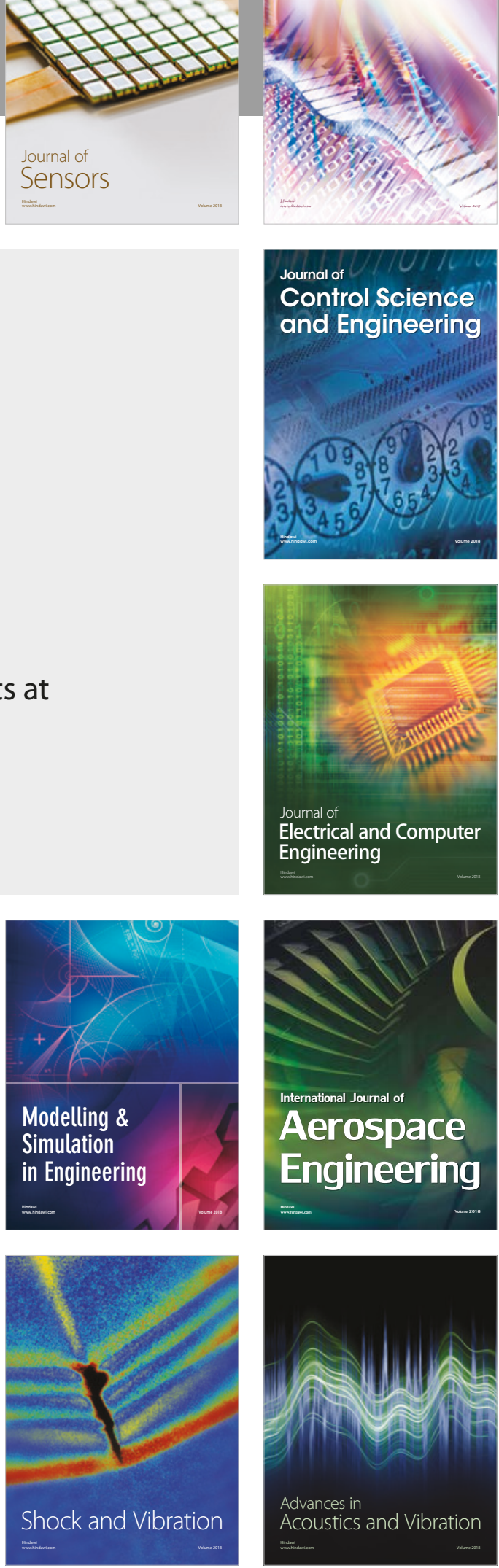